\title{
Influence of milk yield on profitability-A quantile regression analysis
}

\author{
Anke Schorr ${ }^{1}$ and Markus Lips \\ Agroscope, Research Division Competitiveness and System Evaluation, $\mathrm{CH}-8356$ Ettenhausen, Switzerland
}

\begin{abstract}
This paper analyzes the factors that influence the economic success of Swiss dairy farms, as measured by the annual income per family work unit, using panel data regression techniques. Based on more than 5,400 farm-year observations, the main focus of the analysis concerns the milk yield per cow and year as the key explanatory variable, which can be adjusted by the farm manager in the medium term. We apply both a random effects model and a quantile regression based on deciles, which allows us to study the heterogeneity of the sample in greater detail. Consistent with the current literature, the random effects model shows the positive contribution of the milk yield, namely an additional $1,000 \mathrm{~kg} /$ cow results in an increase of CHF 2,660; that is, $6 \%$ of the annual income. The quantile regression reveals that the effect of the milk yield differs between deciles, with a high milk yield being most beneficial for the best-performing farms, accounting for up to CHF 7,210 per $1,000 \mathrm{~kg}$ (where CHF $1=€ 0.86=\$ 1.01$ ). Our analysis further shows the influence of the milk yield on profitability to be highly heterogeneous among Swiss dairy farms, indicating business-specific extension services and not suggesting the requirement for an increased milk yield at each level of economic success.
\end{abstract}

Key words: milk yield, quantile regression, Switzerland, economic performance

\section{INTRODUCTION}

Besides cattle genetics, breeding objectives, and feed composition, milk yield is a key factor for milk production systems. A higher milk yield is usually associated with more intensive production (i.e., higher gross margins per area), but also higher costs (e.g., of concentrate input; Nix, 2015). As a farm manager can adjust the milk yield in the medium term, its influence on a farm's economic success is often analyzed. It is generally considered positive, even based on different

Received January 12, 2018.

Accepted May 26, 2018

${ }^{1}$ Corresponding author: anke.schorr@gmail.com success indicators. According to Vandehaar (1998), a positive relation between the milk yield and profitability persists to very high levels of production for US dairy farms. Winsten et al. (2000) found milk produced per cow to positively affect the profitability of northeastern US dairy farms (for confinement feeding, managementintensive grazing, and mixed production systems), as did Ford and Shonkwiler (1994) for milk sold per cow in relation to the net income of Pennsylvania dairy farms; 2 further studies (Kauffman and Tauer, 1986; Gloy et al., 2002) found similar results for milk yield with respect to return on assets of New York dairy farms. Using the production costs for $1 \mathrm{~kg}$ of milk as an economic indicator for Swiss combined dairy and arable crop farms, Hoop et al. (2015) found that milk yield per cow reduces costs. All mentioned analyses focused on mean value regression, not the entire distribution of economic performance.

Doole and Kingwell (2015) studied ecologically constrained profit maximization for New Zealand dairy farms, based on optimization, not an econometric analysis. They predicted a nonlinear concave dependence of farm profit on milk yield not borne out by the previously mentioned econometric models. Macdonald et al. (2011) found either a linear or a quadratic effect of stocking density on operating profit for New Zealand dairy farms, depending on the milk pricing system.

Economic success of Swiss dairy farms is highly heterogeneous. In 2014, the mean income per family work unit (FWU) of the lowest performing quarter was CHF 14,200, that of the highest quarter CHF 70,000, or 5 times more (Dux et al., 2016).

In contrast to mean value regression, quantile regression (QR) allows for the analysis of different levels, or the distribution, of a dependent variable. Hence, we expect $\mathrm{QR}$ to shed light on potential nonlinear effects of the explanatory variables and better explain the heterogeneity of dairy farms' economic success. Quantile regression has been used in farm management research before (Chidmi et al., 2011; El Osta, 2011; Bakucs et al., 2013; Khanal and Mishra, 2016; Tauer, 2016; Hadrich et al., 2017).

In the present paper, we examined the influence of the milk yield, among other independent variables, on a 
dairy farm's economic success by a 2-fold analysis, comparing a random effects model based on mean values with a panel-based QR. To our knowledge, such a comparison has not previously been used in the literature; similar studies analyzed technical efficiency or relied on single years and variables less focused on production (Chidmi et al., 2011; Hadrich et al., 2017). Our approach will determine whether the use of $\mathrm{QR}$ provides additional insights.

We addressed 2 additional issues. First, we established concentrate input as a relevant determinant in our analysis, reflecting its increased use in Swiss milk production over the last decade (Erdin and Giuliani, 2011). Second, we addressed education in a wider context than prior studies. Besides the educational level of the farm manager and his or her partner, we distinguish education in agriculture, facility management, and other industrial sectors.

\section{MATERIALS AND METHODS}

\section{Data Source}

We based our analysis on information obtained from the Swiss Farm Accountancy Data Network (FADN), which annually retrieves data from more than 3,000 farm operations to assess the economic situation of Swiss agriculture. The data concerning each farm were provided based on operational accounting using direct costing. We focused on specialized dairy farms between 2010 and 2014. During this period, no significant changes in Swiss agricultural policy took place that affected this type of farm. The resulting panel data set is an unbalanced panel consisting of 5,459 observations split between 1,832 farms, with an average of 3 observations per farm over the time period considered. A quarter of the reported farms had either 1 or 5 observations, while the remaining half of the farms was relatively evenly split between 2, 3, and 4 yr of observations.

\section{Dependent Variable: Annual Income per FWU as a Measure of Economic Performance}

The net farm income comprises the remuneration of the family's own labor and capital and is key indicator for economic success for farms mainly operated by family members. Mishra and Morehart (2001) considered operators' labor and management income to be an indicator of the longer-term survival of a farm. Moreover, as the composition of own labor and capital differs among dairy farms, net farm income is of limited suitability as a dependent variable for our analysis. As a consequence, a decomposition of farm income was carried out by deducting the opportunity costs (i.e., the interest rate of federal term bonds) for the remuneration of own capital, which also includes the family owned land. Subsequently, we divide by the number of FWU yielding the annual income per FWU. As in Roesch (2015), this figure is used as a dependent variable. Based on current opportunity costs, the remuneration of labor is 24 times the remuneration of capital (Lips and Gazzarin, 2016) for Swiss farms, underlining the importance of the annual income per FWU.

Key information about the sample is provided in Table 1, including information about the mean values of the decile intervals ordered by the annual income per FWU. For example, if each year comprised 100 observations, the value underneath the third decile would be the mean value of the respective variables attached to the 21st to the 30th largest observations of the income per FWU [e.g., the number of livestock units $(\mathbf{L U})$ attached to those income figures] for each year of the period 2010 to 2014.

On average, a dairy farm features $30.3 \mathrm{LU}$ and 23.1 ha of utilized agricultural area. The average milk yield per cow and year was $6,410 \mathrm{~kg}$, whereas the annual income of a FWU amounts to CHF 42,800 with an average number of $1.33 \mathrm{FWU}$ on a dairy farm (The average exchange rates for 2016 were CHF $1=€ 0.86$ $=\$ 1.01$; https://data.snb.ch). Total farm assets average $853 \mathrm{kCHF}$ and equity tied to own land $75 \mathrm{kCHF}$ (computed as equity capital times the ratio of the value of own land divided by all farm assets). If the decile intervals were ordered according to the annual income, all the discussed variables except FWU-milk yield, agricultural area, number of livestock units, total farm assets, and equity tied to own land - showed an increasing tendency; that is, for 3 out of 10 occasions, the subsequent quantile mean is allowed to be smaller than the preceding one.

\section{Choice of Explanatory Variables and Hypotheses}

Based on the prior literature, we formulated hypotheses and defined 6 sets of variables that were used to explain the economic performance of Swiss dairy farms, as measured by the annual income per FWU. Swiss FADN data contained several hundred time series, so we had to rely on the literature to narrow down our set of variables.

The first set of regional dummies (set $\mathbf{R} ; 7$ variables) based on cantons (Switzerland consists of 26 which are comparable to districts) comprises the location of the farm within 1 of Switzerland's 7 macroregions (i.e., southwestern Switzerland, i.e., Geneva, Vaud, and Valais; "Espace Mittelland," i.e., Berne, Solothurn, Fri- 


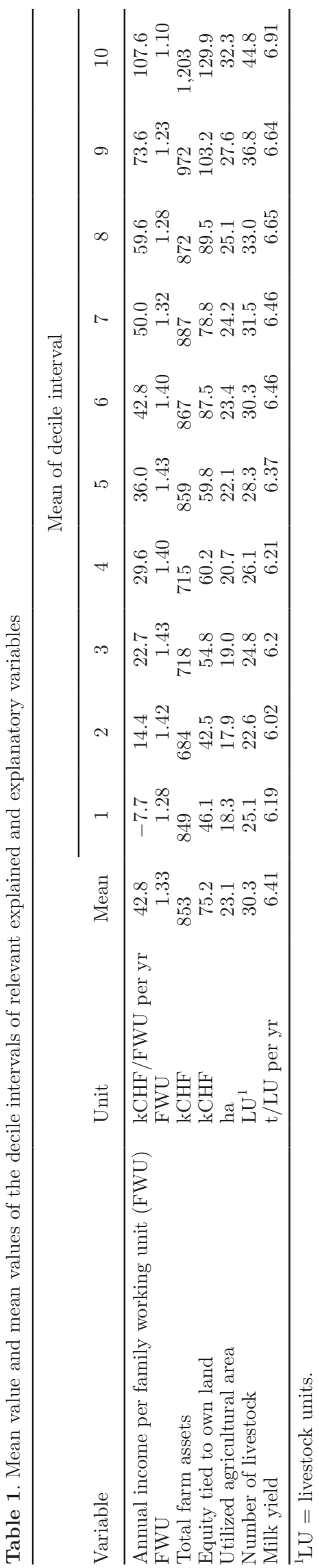

bourg, Neuchâtel, and Jura; Northwestern Switzerland, i.e., 2 half-cantons of Basel and Aargau; Zurich; eastern Switzerland, i.e., Thurgau, St. Gall, Schaffhausen, Grisons, Glarus, and 2 half-cantons of Appenzell; central Switzerland, i.e., Lucerne, Zug, Obwalden, Nidwalden, Uri, and Schwyz; and Ticino; there were no data within the sample for the Ticino macro-region; BFS, 1999) as well as whether or not the farm is located within a mountainous canton (the mountain cantons comprise Glarus, Nidwalden, Obwalden, Uri, Grisons, Ticino, and Valais; RKGK, 2017). We mainly used these variables to control for regional differences in our analysis.

The production technique (set $\mathbf{P} ; 6$ variables) included by the milk price per unit of milk, milk yield per LU, organic production, usage of freestall housing, silage-free production, and cost of concentrate feed per dairy cow. Based on the findings of Kauffman and Tauer (1986), Gloy et al. (2002), Winsten et al. (2000), and Vandehaar (1998), we expected a positive contribution of the milk yield to the economic success of a dairy farm. We also postulated a nonlinear relationship between milk yield and economic success of a dairy farm, based on a modification of the quadratic dependency of stocking rate and profit of a farm per unit of production from Macdonald et al. (2011). For reasons of simplification and comparison with the literature, we opted for a linear relationship and consider this issue in the discussion section.

According to Kauffman and Tauer (1986), purchased feed negatively affects income, which led to our hypothesis that this was also the case for the cost of concentrate input. The results concerning the contribution of organic farming (Khanal and Mishra, 2016; Hadrich et al., 2017) are mixed.

The third set of variables reflects the structural situation (set $\mathbf{S} ; 7$ variables). Based on the work of Kauffman and Tauer (1986), Ford and Shonkwiler (1994), Roesch (2015), and Hadrich et al. (2017) (Table 2), we hypothesized that the farm size, as measured in LU, has a positive effect on profitability. In addition, based on Roesch (2015), the farm area, as reflected by the total farmland owned, natural and artificial grassland, share of rented to total farmland, and stocking density, may positively influence profitability. As it is not evident whether the farm size in LU or in terms of the area of land will have the most significant influence (if any influence is found at all) on economic success, we initially included both sets of related variables. We recognize, however, that in our final specification of the model, one set of variables will ideally prevail. Finally, a farm location in steep terrain triggers subsidies according to Swiss agricultural policy, which may have a negative (higher costs) or positive (additional direct payments) influence on income. 
Three different aspects of diversification are considered (set $\mathbf{D} ; 3$ variables), which were measured using the inverse normalized Herfindahl-Hirschman indices $\left(H_{i}^{n}\right)$ based on the work of Hirschman (1964). The exact construction of the inverse Hirschman-Herfindahl index is described in the Appendix.

The first index $\left(H^{n}{ }_{i, t o t}\right)$ measured the generic total diversification of the farm outside the dairy sector. It was constructed by taking into account the aggregated revenues derived from livestock-related farming except for dairying, cropping-related activities, and agriculture-related activities. The second index $\left(H_{i, p l}^{n}\right)$ measured diversification within crop-related activities (i.e., following several activities rather than just one ag- gregated activity as in the first index). For this index, $\mathrm{n}=13$, assessing the revenues derived from bread and fodder cereal, maize, potatoes, sugar beets, rapeseed, fresh and canned vegetables, fruits and vine, tobacco, roughage, other crops, and forestry. The third index applies the same reasoning to agriculture-related activities (i.e., direct sales, agricultural work for thirdparties, agritourism, or other activities), which leads us to $H_{i, a r}^{n}$ with $\mathrm{n}=4$.

Mishra and Morehart (2001) found overall diversification to negatively affect a farm's economic success, as did Roesch (2015) for certain aspects of diversification within cropping; Khanal and Mishra (2016) found similar results for some agriculture-related activities.

Table 2. Hypotheses concerning the explanatory variables

\begin{tabular}{|c|c|c|c|c|c|c|}
\hline Set & Variable & Reference & Variable & Impact $^{1}$ & $\begin{array}{l}\text { Performance } \\
\text { indicator }\end{array}$ & Hypothesis \\
\hline \multirow[t]{6}{*}{$\mathrm{P}$} & \multirow[t]{3}{*}{ Milk yield } & $\begin{array}{l}\text { Kauffman and Tauer } \\
(1986)\end{array}$ & Milk yield & + & $\begin{array}{l}\text { Operator's labor } \\
\text { and management } \\
\text { income (OLMI) }\end{array}$ & \multirow[t]{3}{*}{$\begin{array}{l}\text { H1. Milk yield } \\
\text { contributes positively. }\end{array}$} \\
\hline & & $\begin{array}{l}\text { Ford and Shonkwiler } \\
\text { (1994) }\end{array}$ & Milk sold & + & Net farm income & \\
\hline & & Vandehaar (1998) & Milk yield & + & Profitability & \\
\hline & Purchased feed & $\begin{array}{l}\text { Kauffman and Tauer } \\
(1986)\end{array}$ & $\begin{array}{l}\text { Purchased feed per } \\
\text { cow }\end{array}$ & - & OLMI & $\begin{array}{l}\text { H2. Purchased feed } \\
\text { contributes negatively. }\end{array}$ \\
\hline & \multirow[t]{2}{*}{$\begin{array}{l}\text { Organic } \\
\text { production }\end{array}$} & $\begin{array}{l}\text { Khanal and Mishra } \\
\text { (2016) }\end{array}$ & $\begin{array}{l}\text { Organic } \\
\text { production }\end{array}$ & - & $\begin{array}{l}\text { Net cash farm } \\
\text { income }\end{array}$ & \multirow[t]{2}{*}{$\begin{array}{l}\text { Contradictory results - } \\
\text { no hypothesis. }\end{array}$} \\
\hline & & Hadrich et al. (2017) & $\begin{array}{l}\text { Organic } \\
\text { production }\end{array}$ & + & Net farm income & \\
\hline \multirow[t]{3}{*}{$\mathrm{S}$} & \multirow[t]{3}{*}{ Size } & $\begin{array}{l}\text { Kauffman and Tauer } \\
(1986)\end{array}$ & $\begin{array}{l}\text { Livestock units } \\
\text { (LU) }\end{array}$ & + & OLMI & \multirow[t]{3}{*}{$\begin{array}{l}\text { H3. Size contributes } \\
\text { positively. }\end{array}$} \\
\hline & & Roesch (2015) & Area & + & Income per FWU & \\
\hline & & Hadrich et al. (2017) & $\mathrm{LU}$ & + & Net farm income & \\
\hline \multirow[t]{3}{*}{$\mathrm{D}$} & \multirow[t]{3}{*}{ Diversification } & $\begin{array}{l}\text { Mishra and Morehart } \\
(2001)\end{array}$ & Diversification & - & OLMI & \multirow[t]{3}{*}{$\begin{array}{l}\text { H4. Diversification } \\
\text { contributes negatively. }\end{array}$} \\
\hline & & Roesch (2015) & $\begin{array}{l}\text { Area of maize and } \\
\text { grassland }\end{array}$ & - & Income per $\mathrm{FWU}$ & \\
\hline & & $\begin{array}{l}\text { Khanal and Mishra } \\
(2016)\end{array}$ & Direct sales & - & $\begin{array}{l}\text { Net cash farm } \\
\text { income }\end{array}$ & \\
\hline \multirow[t]{3}{*}{$\mathrm{O}$} & Full-time farming & $\begin{array}{l}\text { Khanal and Mishra } \\
\text { (2016) }\end{array}$ & Non-farm income & - & $\begin{array}{l}\text { Net cash farm } \\
\text { income }\end{array}$ & \multirow{3}{*}{$\begin{array}{l}\text { H5. Full-time farming } \\
\text { contributes positively. } \\
\text { H6. Wages paid } \\
\text { contribute negatively. } \\
\text { H7. Capitalization } \\
\text { contributes negatively. }\end{array}$} \\
\hline & Wages paid & Roesch (2015) & Number of workers & - & Agricultural income & \\
\hline & Capitalization & $\begin{array}{l}\text { Mishra and Morehart } \\
(2001)\end{array}$ & $\begin{array}{l}\text { Value of } \\
\text { machinery and } \\
\text { production/value } \\
\text { of production }\end{array}$ & - & OLMI & \\
\hline $\mathrm{E}$ & Education & Hadrich et al. (2017) & No education & - & Net farm income & $\begin{array}{l}\text { H8. No or low } \\
\text { education contributes } \\
\text { negatively, whereas } \\
\text { high education } \\
\text { contributes positively. }\end{array}$ \\
\hline
\end{tabular}


Hence, for these 3 aspects of diversification that we considered within our model, we expected a negative contribution to the economic success of a farm.

Another set of variables considered the organizational and financial factors associated with running a farm business (set $\mathbf{O}$; 4 variables), namely the share of farm income compared with the total income available (this share is normalized to the interval zero to unity; it is set equal to zero if the farm income is negative, and equal to unity if the nonfarm income is negative), the share of non-family working units (non-FWU) as a percentage of the total working units, the size of the farm operator's household in terms of consumption units, as well as a capitalization index. The latter is constructed as the ratio of costs related to equipment, building, and machinery, including depreciation, divided by all costs save for personnel costs.

With respect to the organizational aspects of a farm business, based on the prior literature, we expected fulltime farming to positively affect a farm's income (in line with the findings of Khanal and Mishra, 2016), whereas the number of workers (Roesch, 2015) - in our case the non-FWU as well as the size of the operator's family - were expected to contribute negatively. Moreover, Mishra and Morehart (2001) found the capitalization of a dairy farm, as measured by the value of equipment and machinery divided by the value of production, to have a negative effect on a farm's economic success, albeit not a statistically significant one.

The final set of variables (set $\mathbf{E} ; 22$ variables) assessed the education level of the farm operator and his or her partner. Three areas of education - agriculture, facility management, and all remaining sectors - were combined with 5 levels of attainment for agriculture and 3 levels for each of the remaining 2 sectors for both the farm operator and their partner. In this manner, we obtained 22 distinct variables. (Note that any dummy variable related to different types of education on the part of the farm manager and their partner is hard to validate in terms of its significance. The 5 distinct levels of education are no apprenticeship, started apprenticeship, finished apprenticeship, further education after apprenticeship, and university-level studies. The first and last 2 levels of the 5 were aggregated for the 3-level assessment of education.) Based on prior literature assessing the effect of education on a farm's economic success, we hypothesized the positive contribution of a high level of education (Mishra and Morehart, 2001; El Osta, 2011; Khanal and Mishra, 2016; Hadrich et al., 2017), whereas a lack or low level of education is expected to have a negative effect (Hadrich et al., 2017). Our analysis therefore involves a total of 49 explanatory variables.
It should be noted that the following aspects were outside the scope of our study because they could not easily be linked to FADN data: climate, soil, and weather data, as well as the genetic resources (e.g., breeds and their genetic value) of the dairy cattle on each farm. For cattle genetics, we assumed that 1 (dairy) LU represented a combination of animals representative of Swiss dairy cattle holdings in 2014: $48 \%$ Swiss Herdbook breed, 38\% Swiss Brown, 13\% Holstein, and 1\% Eringer (Schweizer Milchproduzenten, 2014).

The hypotheses regarding whether we assume a specific explanatory variable to contribute negatively or positively to the economic success of dairy farms, as detailed in the above classification of the tentative explanatory variables, are summarized in Table 2.

\section{Choice of Panel Data Model and Endogeneity}

In terms of all our explanatory variables and the annual income per FWU, the cross-sectional variance component was greater than the temporal component (Table A1), which indicates that a random effects model is preferred; this is a frequently used approach in the literature. The applicability of a pooled ordinary least squares (OLS) model was tested by means of a Breusch-Pagan Lagrange multiplier test (Breusch and Pagan, 1980) and rejected. If a random effects model is indeed applicable, it has the additional advantage of allowing the straightforward inclusion of time-invariant explanatory variables. Moreover, the resulting model will be more efficient than its fixed effects counterpart. If both a random effects and a fixed effects model are applicable, the random effects model is more efficient, resulting in a narrower confidence interval for its computed coefficients. We tested the applicability of a random effects model in multiple ways, namely using a straightforward Hausman test (Baltagi et al., 2003; "If this standard Hausman test rejects the null hypothesis that the conditional mean of the disturbances given the regressors is zero, the applied researcher reports the fixed effects estimator. Otherwise, the researcher reports the random effects estimator"), a HausmanTaylor model [Hausman and Taylor, 1981; Baltagi et al., 2003; in the context of the economic success of dairy farms, Gloy et al. (2002) argue that size should be considered an endogenous variable, as it is not clear from the outset whether economic success influences size or vice versa, or, more generally, which direction of influence would prevail, as both could be present to a different extent], a Mundlak-type correlated random effects model (Mundlak, 1978), and a fixed effects vector decomposition (FEVD) model (Greene, 2011). The different models employed were also chosen to address 
endogeneity: The Mundlak model tests for evidence of a correlation between a time-invariant unobservable and our regressors. If we test coefficients of the HausmanTaylor model, which uses instrumental variables for potentially endogenous regressors versus the coefficients of a random effects model, we further determine whether the use of a random effects model, which requires exogeneity of regressors and the individual effects, is appropriate. As the term of an endogenous variable can be considered an explanatory variable correlated with the error term of a regression, we will determine and indicate correlations between the error term of the random effects model and explanatory variables in the Appendix. The choice of a random effects model will further inform our choice of model for the QR.

\section{Variable Selection}

Based on our entire set of 49 independent variables, the process of selecting variables for the model depends on the set each variable belongs to. For a general discussion of backward and forward selection using a wide range of selection criteria, see chapter 4 of Harrell (2001). We use a modified version of both the forward and backward selection criteria that fit our purpose and are specified below.

For sets $\mathrm{S}$ and $\mathrm{R}$, all the variables were initially included in the model. Subsequently, a variable was excluded if 2 conditions were met. First, if its absence did not decrease the explanatory power of the model as measured by the coefficient of determination adjusted by the number of variables and, second, if its absence did not jeopardize the applicability of a random effects model. As noted in the previous paragraph, the variable that we sought to explain (annual income per FWU) warranted a random effects model so as to be able to assess "all aspects" of its variance; therefore, we used this type of model. This corresponds to a modified version - in terms of the exclusion criteria - of backward exclusion.

Variables from the remaining sets $(\mathrm{P}, \mathrm{D}, \mathrm{O}$, and $\mathrm{E})$ were added to the model if the explanatory power of the model, as assessed using an adjusted coefficient of determination as above, was not decreased, the variable itself yielded a significant contribution (as assessed by a $t$-test), and the applicability of a random effects model was maintained. This in turn corresponds to a modified version - in terms of the inclusion criteria - of forward selection.

We chose to use different (backward and forward) selection algorithms to maintain as many structural and regional variables as possible, as well as to include less variables from the additional sets of variables $(\mathrm{P}$, $\mathrm{D}, \mathrm{O}$, and $\mathrm{E})$. The results of the models include a minimum number of explanatory variables according to the selection criteria outlined above. To assess whether the selection criteria described above do not lead to the issue of overfitting, we performed an out-of-sample test of the model.

\section{Panel Quantile Regression and the Presentation of Its Coefficients}

The QR method was first introduced by Wagner (1959), before being taken up by Bassett and Koenker (1978) and Koenker and Bassett (1978).

The QR aims to compute the influence of a set of explanatory variables at a certain point in the distribution of a dependent variable. One could, for example, use QR to analyze how a set of variables influences the upper and lower quartiles as well as the median of a variable measuring the economic success of a dairy farm. The actual computation of the coefficients measuring the influence of the explanatory variables involves minimizing a loss function $F[\tau ; y(i), x(i) ; \beta]$ depending on the quantile $\tau$ of the distribution. This, as an equation [the equation does not directly translate to the case of panel data, but we obtain an indication for pooled panel data if we replace the index $i$ with a pair of indices $(i, t)]$ that reads:

$$
\min _{\beta \in R^{P}} \sum_{i \in\left(i: y_{i} \geq x_{i}^{T} \beta\right)}^{N} \tau\left|y_{i}-x_{i}^{T} \beta\right|+\sum_{i \in\left(i: y_{i} \geq x_{i}^{T} \beta\right)}^{N}(1-\tau) \mid y_{i}-x_{i}^{T} \beta,
$$

where $\beta$ is a set of $\mathrm{p}$ rational numbers, hence an element of $R^{P}$, regression factors, which minimize the objective function; $\tau$ indicates the quantile of the distribution; $y$ is the variable to be explained; and $x$ is the matrix of explanatory variables. The algorithms for this technique were implemented in different ways [e.g., based on a semiparametric method using empirical likelihoods, as in Wang and Fygenson (2009), or based on the asymmetric Laplace distribution, as in Geraci and Bottai (2007)], mainly because the involved optimization problem does not have a straightforward analytical solution. The QR was later extended for use with panel data (fixed effects panel data case: Koenker, 2004; Abrevaya and Dahl, 2008; Lamarche, 2010; Canay, 2011; Galvao, 2011; Kato et al., 2012; Arellano and Bonhomme, 2016; random effects panel data case: Geraci and Bottai, 2007; Wang and Fygenson, 2009; Kim and Yang, 2011; Galvao and Poirier, 2017). We choose the QR random effects estimator described by Geraci and 
Table 3. Coefficients of the random effects model for annual income per family working unit $(\mathrm{CHF} / \mathrm{FWU})^{1}$

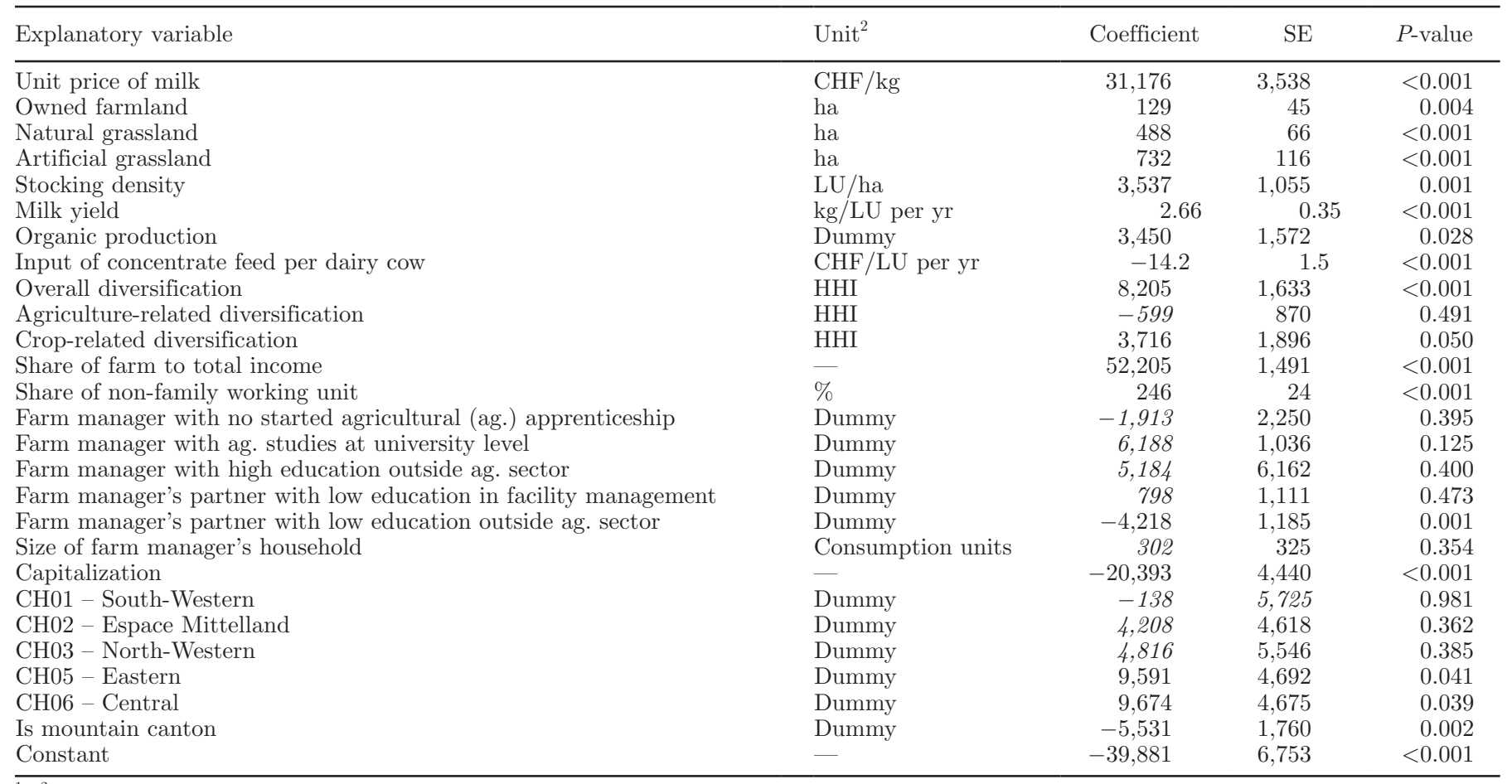

${ }^{1} R_{\text {overall }}^{2}=41.03 \%$; Hausman: $P$-value $=21.94 \%$; Hausman-Taylor model: $P$-value $>99 \%$; Mundlak: $P$-value $=52.45 \%$; Fixed effects vector decomposition: $P$-value $>99 \%$; Breusch-Pagan test: $P$-value $=0 \%$. Coefficients in italics denote a $P$-value greater than $10 \%$.

${ }^{2} \mathrm{LU}=$ livestock unit; HHI $=$ Hirschman-Herfindahl index.

Bottai (2014). This type of QR estimator agrees with the choice of a random effects model explained in the preceding paragraph.

We used deciles of income distribution as quantiles. Given the high number of observations in our data set, we chose quantiles that offered a reasonable resolution (as opposed to, for example, quartiles with too little or centiles with too much detail) of the results as well as a smooth path for the resulting coefficients along the income distribution of dairy farms (see Table A2 in the Appendix for decile values of all relevant variables).

In addition, we also structured our presentation of the results derived using QR. This was not a methodological choice, but rather a choice to present clearly arranged results to the reader. Based on deciles and a set of $p$ regressors, we obtained (10-1) $\times p$ coefficients. To achieve a more structured overview of the results, we displayed 1 overall coefficient for all the variables where the minimum and the maximum coefficients differed by less than $1 \%$ (as a formula: $2 \cdot[\max \tau(\beta \mathrm{j}, \tau)$ $-\min \tau(\beta \mathrm{j}, \tau)] /|\max \tau(\beta \mathrm{j}, \tau)+\min \tau(\beta \mathrm{j}, \tau)|>1 \%$ for regressor $\mathrm{j}$ ) and a series of coefficients otherwise. This criterion does not imply the statistical difference of the minimum and maximum coefficients over all the quantiles. By means of a Wald-type test, as described by
Koenker and Bassett (1982), we will additionally show whether the minimum and maximum coefficients were statistically different.

\section{RESULTS}

Table 3 presents the results of the random effects model of the annual income per FWU. In our random effects model, approximately two-fifths of the variance can be explained $\left(\mathrm{R}^{2}=41 \%\right)$. The overall significance of the random effects model was assessed using a Wald test as being very high $(P<0.001)$.

The admissibility of a random effects model was demonstrated using the Hausman test with a $P$-value of $21.9 \%$, the application of the Hausman-Taylor model with a subsequent Hausman test with a $P$-value $>99 \%$, and the application of the Mundlak-correlated random effects model with the hypothesis of a coefficient of the time average regressors different from zero being rejected with a $P$-value of $52.45 \%$. Both the admissibility of the Hausman-Taylor and the Mundlak model indicate that endogeneity was not of strong importance for our chosen set of variables for the random effects model. We further addressed this issue by indicating correlations between the error term of the random ef- 
fects model and the explanatory variables in Appendix Table A3. The FEVD model is consistent with the random effects model, although the random effects model is more efficient $(P>0.99)$. The statistics derived from the Breusch-Pagan test with a $P$-value less than $0.1 \%$ rule out the possibility of using a pooled OLS model. To determine how the explanatory power of the model changes if we changed its underlying time frame, we performed an out-of-sample test for the year 2009, whereas the original time frame of the model is from 2010 through 2014. Even though the out-of-sample year still had a different milk market, based on quota, in place for most of the time, the resulting coefficient of determination is $35 \%$, as opposed to of $41 \%$ of the original model.

The milk yield per cow and year has a strongly significant positive influence on the farm income. An additional tonne of milk per LU and year increases the annual income by CHF 2,660 (i.e., by one-tenth). In addition, the milk price, area of grassland, overall diversification outside of dairying, full-time farming (i.e., a high share of farm to total income), and the share of non-FWU are all highly significant positive determinants of financially successful farms. Other positive determinants include owned farmland, stocking density, organic production, and diversification within cropping activities. The regions with an additional positive income are eastern and central Switzerland (as compared to the canton of Zürich, which forms the base case).

A farm's capitalization, as measured by the corresponding index, and the input of concentrate feed per cow contribute highly negatively to the economic performance of a farm. Other significantly negative contributors include a low level of education on the part of the farm manager's partner outside of agriculture as well as the location of the farm in a mountainous canton.

The effect per additional unit, or the effect after an increase in the respective variable by 1 standard deviation or by $10 \%$ of its mean value, results in the following order of contribution, where we only consider those variables with a statistically significant effect. After a change by 1 standard deviation, the 2 factors contributing the most in a positive manner are the share of the farm total income $(14.8 \mathrm{kCHF}$ or $39.3 \%)$, area of natural grassland (5.1 $\mathrm{kCHF}$ or $13.6 \%$ ), and share of non-FWU (5.1 kCHF or $13.5 \%$ ), whereas the factors contributing most negatively are the concentrate input per cow $(-5.0 \mathrm{kCHF}$ or $-13.2 \%)$ and capitalization $(-2.3 \mathrm{kCHF}$ or $-6.0 \%)$.

If we consider an increase by 1 additional unit, the dummy variables realize the highest effect, almost by definition, as 1 additional unit for a dummy vari- able indicates the presence of a respective effect, for example, organic production. Thus, the factors with the highest positive contribution are the location of the farm in central $(9.7 \mathrm{kCHF}$ or $25.7 \%$ ) or eastern Switzerland (9.6 kCHF or $25.5 \%$ ), whereas the location in a mountainous canton is least favorable $(-5.5$ $\mathrm{kCHF}$ or $-14.7 \%)$. If the farm manager's partner has a low level of education outside the agricultural sector, an income reduction in agriculture of $-4.2 \mathrm{kCHF}$ or $-11.2 \%$ was seen. Leaving aside the dummy variables, the 2 determinants with the strongest positive influence were the stocking density (3.5 $\mathrm{kCHF}$ or $9.4 \%)$ and the share of farm income to total income $(0.5 \mathrm{kCHF}$ or $1.4 \%$ ), whereas the determinant with the highest negative effect was capitalization $(-0.2 \mathrm{kCHF}$ or $-0.5 \%)$.

For a $10 \%$ increase, the variables contributing most positively were again the share of the farm income to the total income $(3.7 \mathrm{kCHF}$ or $9.7 \%)$ as well as the milk price $(1.9 \mathrm{kCHF}$ or $4.9 \%)$ and milk yield (1.7 $\mathrm{kCHF}$ or $4.5 \%$ ), whereas the most negative contributors were capitalization $(-1.3 \mathrm{kCHF}$ or $-3.5 \%)$ and the concentrate input per cow $(-0.8 \mathrm{kCHF}$ or $-2.2 \%)$. All contributions were considered ceteris paribus.

Some 6 explanatory variables from the QR model show differences above $1 \%$ and were thus represented as a series of coefficients in Table 4 . These were the area of owned farmland and of natural and artificial grassland, share of non-FWU, concentrate input per cow, and milk yield. The milk yield was the only explanatory variable whose coefficients changed significantly for the least and the most successful farms. Therefore, milk yield arguably showed the most diverse results over the range of economic success that we analyzed. Using a Wald test to assess the statistical significance between the minimum and maximum coefficients among the quantiles of the explanatory variables resulted in a statistical difference for the milk yield, where the difference between the 1 st and the 9 th decile yielded a $P$-value of less than 0.001, as well as for the concentrate input per cow, where the difference between the 3nd and the 7th decile yielded a $P$-value of $2.5 \%$. An overview of the significance of the differences between maximum and minimum coefficients of variables where coefficients were considered varying are given in Table 5 below.

Although the estimated coefficients for the different types of farmland were in the range of less than $10 \%$, the other variables showed coefficients differing by at least $20 \%$. The milk yield contributed strongly to the annual income per FWU for the higher deciles, whereas the effect was significantly negative for the lowest decile. The concentrate input per cow reduced the income for all the deciles, albeit to varying degrees, especially around the lower end of the income distribution. The 


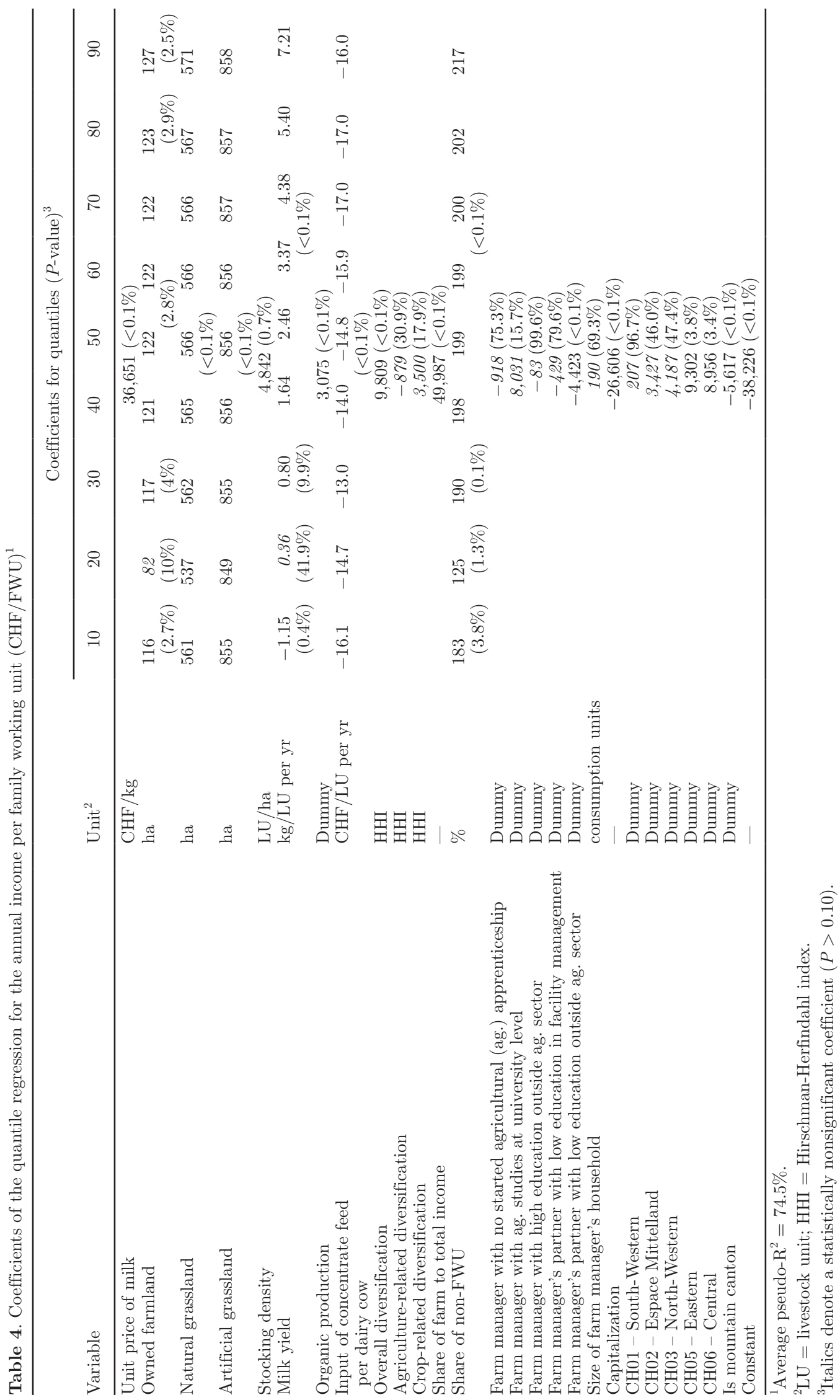


share of non-FWU showed a positive result for all the deciles.

For the 2 variables with statistically different minimum and maximum coefficients, namely the milk yield and concentrate input per cow, we determined the range of the contribution to the mean income per FWU in absolute (CHF/FWU) and relative terms, if we increased the (mean decile) value of the respective variable by $10 \%$. For the milk yield per cow, the absolute contribution ranges from $-0.7 \mathrm{kCHF}$ for the lowest-performing decile to $4.9 \mathrm{kCHF}$ for the best-performing decile. In relative terms, this corresponded to a reduction of $21.1 \%$ for the decile of lowest income per FWU to an increase of $5.4 \%$ for the best-performing decile. We matched the coefficient of the $i$ th decile to the mean values of the $(i-1)$ th to the $i$ th decile, which are noted under decile $i$ in Table 1. For the concentrate input, the range of absolute contributions to income per FWU ranges from $-1.1 \mathrm{kCHF}$ for the lowest-performing decile of the income distribution to $-0.9 \mathrm{kCHF}$ for the best-performing decile. In relative terms, this amounts to a decrease of $32.3 \%$ for the lowest decile of the income distribution and a decrease of $1.0 \%$ for the highest decile.

\section{DISCUSSION}

The discussion addresses 5 issues. First, we focus on the result for milk yield, second further results are discussed, third a comparison to cost analysis is made, fourth we compare our results to other applications of quantile regressions, and, finally, we provide a future outlook.

\section{Milk Yield}

Referring to Table 2, we can state that hypothesis H1 is confirmed for our random effects model. The positive effect of the milk yield is in agreement with the results of previous studies (Kauffman and Tauer, 1986; Ford and Shonkwiler, 1994; Vandehaar, 1998; Winsten et al., 2000; Gloy et al., 2002), as well as in the context of an explanation of the mean economic success of a dairy farm over 1 or several years. The application of the random effects model in conjunction with the QR model can also be seen as a form of sensitivity analysis. Whereas the random effects model aims to explain the mean value of the income per FWU, QR allows us to analyze points of the income distribution. The set of significantly positive and significantly negative coefficients for milk yield obtained by the QR provides a more detailed picture than the single coefficients obtained by previous studies. Bearing in mind that the mean values of milk yield of the decile intervals are relatively close to each other, varying between 6.02 and $6.91 \mathrm{t} / \mathrm{LU}$ per year (see Table A2 in the appendix), the set of coefficients points to highly differing effects of milk yield on income per FWU across the quantiles. The resulting negative and positive coefficients could emerge from a linearized nonlinear effect of milk yield on profitability, as was shown in the study by Doole and Kingwell (2015).

As a further sensitivity analysis, we used milk yield both as a quadratic and a linear term in both the random effects model and the panel QR. Results are as shown in Table A4 in the appendix. All linear and quadratic terms were statistically significant at least the $10 \%$ level except the quadratic terms of the seventh, eighth, and ninth quantiles. More importantly, the QR model yielded again quantile-specific coefficients rather than 1 coefficient for the whole distribution.

For the random effects model, a maximum was obtained for $11.1 \mathrm{t}$ of milk per cow and per year. This means that, for more than $99.5 \%$ of the observed dairy farms, an increase in milk yield would increase profitability according to the random effects model. At a milk yield below this value, it is increasingly profitable to produce more milk; QR reveals that, at each decile of the profitability distribution, it is suboptimal to reach a milk yield greater than the local maximum. For example, profits decrease for the first (lowest-income) decile if a milk yield above $6.1 \mathrm{t}$ of milk per cow per year is obtained. Starting from the fourth decile up to the eighth, an increase in milk yield is essentially profitable, as the local maximum is rarely reached in terms of observed milk yield. For the ninth decile, increasing the

Table 5. Assessment of statistical differences between quantiles for variables with nonconstant coefficients

\begin{tabular}{lcc}
\hline Variable & $\begin{array}{c}\text { Significance of Wald test } \\
(P \text {-value })\end{array}$ & $\begin{array}{c}\text { Quantiles compared } \\
\text { (minimum vs. maximum coefficient) }\end{array}$ \\
\hline Owned farmland & $59.3 \%$ & 20,90 \\
Natural grassland & $55.2 \%$ & 20,90 \\
Artificial grassland & $51.9 \%$ & 20,90 \\
Milk yield & $<0.1 \%$ & 10,90 \\
Input of concentrate feed per dairy cow & $2.5 \%$ & 30,70 \\
Share of non-family working unit & $56.9 \%$ & 20,90 \\
\hline
\end{tabular}


milk yield is always profitable, as a maximum profit is only obtained at an infinite milk yield.

In fact, this is what the linear random effects model and $\mathrm{QR}$ indicated, too. For the first decile, increasing milk yield means less profitability; starting from the fourth decile, increasing milk yield is very significantly profitable. We considered the linear analysis as being clearer for the reader at first sight in terms of when an increase in milk yield is profitable, but it is essentially the same information conveyed by both the linear and quadratic model. Based on results, we observed that the differences between quantiles are more important than the functional form (i.e., the choice between a linear or nonlinear relationship).

\section{Other Results}

For all the explanatory variables except for the milk yield, the results are discussed in the context of our hypotheses, and an attempt will be made to explain the identified contradictions. In a brief comparison, we contrast the significant coefficients explaining the mean value of the income per FWU with those from the fifth decile used in the QR (i.e., the median of the income distribution). The median annual income per FWU stands at $39.04 \mathrm{kCHF}$ (i.e., $8 \%$ less than its mean).

Besides the 6 variables with quantile-specific results, the remaining 20 coefficients were similar in terms of their significance and value between the random effects model and the QR. All the coefficients that were statistically significant in the QR were also statistically significant in the random effects model. All the coefficients of the random effects model were in the $95 \%$ confidence interval of the QR coefficients related to the median of the income distribution. All the coefficients related to the median of the income distribution, except for the ratio of farm to total income, were in the $95 \%$ confidence interval of the respective coefficients of the random effects model. The coefficients still showed small differences, which is to be expected, given that they explain a different property of the distribution; those related to the random effects model explain the mean, whereas the QR coefficients explain the median. Focusing on the quasi-constant coefficients significant in both models, 4 coefficients were greater for the $\mathrm{QR}$ than for the random effects model (milk price, stocking density, diversification outside the dairy sector, and location in the first macro region), whereas 10 coefficients were smaller (organic production, diversification in cropping, share of farm to total income, capitalization, low education of farm management's partner outside the agricultural sector, location in the second, third, fifth, and sixth macro regions, and location in a mountainous canton).
Comparing our results with those presented in the literature, we distinguished 2 groups of coefficients. The first group comprised those variables with a single, statistically significant, coefficient in both models (milk price, stocking density, generic diversification outside the dairy sector, the farm being a full-time operation, organic agriculture, and capitalization). For these coefficients, a comparison of our results with those found in the literature is rather straightforward. The identified contribution of organic agriculture is in opposition to the finding of Khanal and Mishra (2016) but in line with Hadrich et al. (2017), who performed an analysis closer to ours by focusing on dairy farming and not on organic farming in general. The diversification aspects that in our model strengthen economic success contradict the results of Mishra and Morehart (2001) and Roesch (2015), if for the latter we take larger areas of crop production as a sign of stronger diversification. The measure of diversification closest to ours is used by Mishra and Morehart (2001), although 57\% of their sample of US dairy farms were located in the rather flat Midwest region and $27 \%$ in the Northeast. Their sample showed a higher weight toward valley-like regions, for which our model showed a negative contribution of overall diversification. If we restricted our model to the valley region, the diversification aspects would turn out to be negative (results not reported). Capitalization was confirmed to have a very significantly negative influence on a dairy farm's economic performance, whereas the negative effect seen in the study by Mishra and Morehart (2001) was statistically insignificant. Our results on diversification into paraagricultural activities, such as direct sales, also showed a negative contribution to economic success, which is in line with the findings of Khanal and Mishra (2016). The positive relation between stocking density and a dairy farm's economic success was in line with the results of Macdonald et al. (2011), albeit they performed a further differentiation with respect to whether stocking density contributes linearly or quadratically, which turned out to depend on the underlying milk pricing system assumed in their study (we discussed a related point of linear and quadratic contribution in the context of milk yield in the first part of the discussion section). Stocking density can be considered as a function of underlying land productivity, which in our data set was not represented, but is also legally constrained by the amount of manure per area (Swiss Confederation, 1991) and optimal intake of concentrate.

The second group focused on all the variables with a set of coefficients for the $\mathrm{QR}$ as per our presentation, which consisted of either positive or negative statistically significant coefficients. This set comprised variables related to farm size (i.e., owned farmland, 
natural and artificial grassland), the share of non-FWU on the farm, and the input of concentrate feed per cow. The positive contribution of all the size-related aspects, whether based on area or the number of LU, was consistent throughout the literature (Kauffman and Tauer, 1986; Ford and Shonkwiler, 1994; Winsten et al., 2000; Mishra and Morehart, 2001; Gloy et al., 2002; Roesch, 2015; Hadrich et al., 2017). The positive contribution that our model yielded for the share of non-FWU contrasts with the reports by Kauffman and Tauer (1986), Gloy et al. (2002), and Roesch (2015). However, the variables that those authors chose were slightly different from ours in that they considered wages paid or the absolute number of hired workers. Roesch (2015) found a negative significant contribution only for agricultural income, where it might make sense, as wages paid to workers directly contributed negatively to this figure. In the study of Kauffman and Tauer (1986), the most significantly negative results were obtained for an analysis of return on equity and management income per operator per cow, whereas the explanatory variable used in both cases was cost of hired labor per cow. Gloy et al. (2002) use cost of hired labor per work unit as an explanatory variable. The technical reason for the negative coefficient of cost of hired labor per work unit in their analysis and the positive coefficient for percentage or number of work units of hired labor in ours was a significant negative correlation between both quantities. The more hired work units there are, the less expensive one unit tends to be. Our results concerning the negative contribution of the concentrate input are in alignment with those of the study by Kauffman and Tauer (1986).

In summary, we can state that hypotheses $\mathrm{H} 4$ and $\mathrm{H} 6$ were rejected, keeping in mind that the choice of variables is not exactly identical throughout the referenced literature. Hypotheses H2, H3, H5, H7, and H8 were confirmed for both our models.

\section{Comparison to Cost Analysis}

In addition to comparing the results of models focusing on the economic success of a dairy farm, we also compared the results of our models related to economic success with those of models explaining the costs of dairy production.

Hoop et al. (2015) analyzed the determinants of the full cost of producing $1 \mathrm{t}$ of milk in Swiss dairy farms. The cost determinants could be expected to be opposite those of the income per FWU, in the sense that if a determinant leads to increased costs it might lead to reduced income. Yet, the results could be more complex, as a determinant could, for example, increase costs, but also increase revenues, albeit not to the same extent. We determined the milk yield and size - in LU and area-reduced costs. Silage-free production, assets including machinery, buildings, and equipment, superior conditions with respect to animal welfare, the age of the farmer, and the share of hired workforce all increased costs. According to our analysis, with respect to the milk yield and size of the enterprise, decreased costs translated into higher income. However, the increased revenues achieved via the labor of hired work units seemed to outweigh their increased cost, as our results indicated the overall positive contribution of hired labor to economic success.

\section{Comparison to QR Analyses}

With respect to the literature, wherein QR was used as a method, we were interested in the share of coefficients that vary among the quantiles. Initially, we had no expectations regarding whether the coefficients would vary for each explanatory variable or for none of the variables. In the absence of an exact analytical solution, strongly varying or quasi-constant coefficients could both be due to the convergence behavior of the algorithm of the respectively used QR model. In the former case (varying coefficients) oscillation between the 2 final values could occur with a very slow convergence, whereas in the latter case (quasi-constant coefficients) the initial value might also be the final value of the algorithm, meaning that the convergence criterion did not improve throughout the steps of the algorithm. Although our choice of model was motivated as previously described (QR-random effects case), we might still obtain an indication of the better or worse convergence properties of other QR models and their algorithms.

El Osta (2011) showed results similar to ours in the sense that a quarter of the coefficients of the explanatory variables for the farm household income showed an increasing or decreasing tendency over the quantiles; the remaining variables showed statistically insignificant results for most quantiles. For the QR conducted by Khanal and Mishra (2016), the coefficients of 7 out of 17 explanatory variables declined or increased over the income distribution, whereas the remaining coefficients did not show any particular trend or remain statistically insignificant. Hadrich et al. (2017) conducted the analysis closest to ours by performing a $\mathrm{QR}$ on the net farm income of dairy farms. In their study, 3 (i.e., a sixth) of the coefficients of their explanatory variables showed a linear tendency, whereas the remainder either remained statistically insignificant or showed no particular tendency. Overall, the share of 
the coefficients displaying a linear tendency along the distribution seems similar to ours, whereas the coefficients that showed no such tendency did not stay constant for all the quantiles but instead fluctuated more than the ones obtained in our model. The property of resulting in quasi-constant coefficients, either statistically significant or otherwise, for all the quantiles was a useful property of the algorithm that we chose.

We also assessed the extent to which our QR results are in agreement with the literature. Hadrich et al. (2017) complemented their analysis of the mean values of the net wealth and net income of US dairy farms with a QR. They concluded that, for the net worth, the size of the operation had a positive and increasing effect, as did the college education and the age brackets of the farmer from $35 \mathrm{yr}$ old onward. For net farm income, the size of the operation and organic production showed a higher effect for more successful farms. The size effect agrees with the results we obtained, whereas the effect of organic farming was qualitatively in line with our analysis. Several QR coefficients in the study of Hadrich et al. (2017) showed varying values per quantile without showing any directional trend, corresponding to the case of the 20 variables that we showed as quantile-independent, taking into account the fact that the relative differences in size between the single coefficients over the quantiles were much smaller in our case.

\section{Outlook}

In relation to consulting or extension services provided to dairy farmers, our results imply that the individual situation of each farm needs to be considered. Consulting needs to assess each farm's situation individually, by considering its specific characteristics, a major characteristic being its position within the distribution of economic performance of its peers. General advice, such as additional milk yield being beneficial, was not supported by our findings. To determine whether the identified effect was specific to Swiss dairy farms, it would be interesting to conduct a similar analysis in other countries. In addition, it remains to be understood how the path leading from a less-successful to a more-successful dairy farm could be described, as well as what role further nutritional factors and genetics could play. Constructing a production function of Swiss dairy production could shed additional light on the contributions of the latter 2 factors.

\section{CONCLUSIONS}

The present paper analyzed the determinants of the annual income per FWU of Swiss dairy farms based on
FADN data by means of 2 regression types: a random effects model and a QR based on deciles. The milk yield and concentrate input played a significant role in both the random effects model and the QR. Although the random effects model showed the significant positive effect of the milk yield on income, the QR revealed a much more detailed picture. For 6 out of 26 explanatory variables, the $\mathrm{QR}$ revealed differing effects (i.e., a linear tendency in coefficients across the deciles) instead of a single coefficient, as was the case for the random effects model. The effect of the milk yield on income increased with income. With an increase of almost CHF 7,200 per additional tonne of milk yield per LU (i.e., a $16 \%$ increase compared with the mean income of dairy farms), the best-performing decile benefited strongly, which suggests a thorough understanding of production technology and economic performance on those farms. This thorough expertise was underscored by the significance of managerial ability, as measured directly by the educational level of the farm operator and his or her partner, by the increasing and significant influence of milk yield, which (next to input prices, land productivity, and cattle genetics) indirectly relates to managerial ability. For the least-successful decile of dairy farms, the contribution of an additional kilogram of milk was negative, whereas for the 2 subsequent deciles statistically we found no effect of a higher milk yield on income. More generally, the analysis using 2 regression models revealed that the data include a kind of heterogeneity, which cannot be addressed by a regression focusing on the mean value. Our results confirmed the contribution that $\mathrm{QR}$ can make in terms of additional knowledge gained, in our case concerning the milk yield as a key factor in milk production systems.

\section{ACKNOWLEDGMENTS}

The authors are grateful to the FADN team at Agroscope for providing the data used in this study. The authors also wish to thank Nadja El Benni and Swetlana Renner (Agroscope) for their helpful comments.

\section{REFERENCES}

Abrevaya, J., and C. M. Dahl. 2008. The effects of birth inputs on birthweight: Evidence from quantile estimation on panel data. J. Bus. Econ. Stat. 26:379-397.

Arellano, M., and S. Bonhomme. 2016. Nonlinear panel data estimation via quantile regressions. Econom. J. 19:C61-C94.

Bakucs, Z., S. Bojnec, I. Ferto, and L. Latruffe. 2013. Farm size and growth in field crop and dairy farms in France, Hungary and Slovenia. Span. J. Agric. Res. 11:869-881.

Baltagi, B. H., G. Bresson, and A. Pirotte. 2003. Fixed effects, random effects or Hausman-Taylor. A pretest estimator. Econ. Lett. 79:361-369.

Bassett, G., and R. Koenker. 1978. Asymptotic theory of least absolute error regression. J. Am. Stat. Assoc. 73:618-622. 
BFS. 1999. Die sieben Grossregionen der Schweiz. [The seven macro-regions of Switzerland.] Swiss federal statistical office. Accessed Jul. 19, 2017. https://www.admin.ch/gov/de/start/dokumentation/ medienmitteilungen.msg-id-10585.html.

Breusch, T. S., and A. R. Pagan. 1980. The Lagrange multiplier test and its applications to model specification in econometrics. Rev. Econ. Stud. 47:239-253.

Canay, I. A. 2011. A simple approach to quantile regressions for panel data. Econom. J. 14:368-386.

Chidmi, B., D. Solis, and V. E. Cabrera. 2011. Analyzing the sources of technical efficiency among heterogeneous dairy farms: A quantile regression approach. J. Dev. Agric. Econ. 3:318-324.

Doole, G. J., and R. Kingwell. 2015. Efficient economic and environmental management of pastoral systems: Theory and application. Agric. Syst. 133:73-84.

Dux, D., D. Schmid, P. Jan, D. Hoop, and S. Renner. 2016. Die wirtschaftliche Entwicklung der schweizerischen Landwirtschaft 2015: Hauptbericht Nr. 39 der Zentralen Auswertung von Buchhaltungsdaten Stichprobe Einkommenssituation [The economic development of Swiss agriculture 2015: Main report no. 39 of the Swiss FADN]. Agroscope Transfer. 143. Agroscope, Ettenhausen, Switzerland.

El Osta, H. S. 2011. The impact of human capital on farm operator household income. Agric. Resour. Econ. Rev. 40:95-115.

Erdin, D., and S. Giuliani. 2011. Kraftfutterverbrauch der gemolkenen Kühe. [Intake of concentrate feed of milked cows.] LMZ 2011:4-8.

Ford, S. A., and J. S. Shonkwiler. 1994. The effects of managerial ability on farm financial success. Agric. Resour. Econ. Rev. 23:150-157.

Galvao, A. F. 2011. Quantile regression for dynamic panel data with fixed effects. J. Econom. 164:142-157.

Galvao, A. F., and A. Poirier. 2017. Quantile regression random effects. Accessed Jul. 11, 2017. https://papers.ssrn.com/sol3/papers .cfm?abstract_id=2746894.

Geraci, M., and M. Bottai. 2007. Quantile regression for longitudinal data using the asymmetric Laplace distribution. Biostatistics $8: 140-154$.

Geraci, M., and M. Bottai. 2014. Linear quantile mixed models. Stat. Comput. 24:461-479.

Gloy, B., J. Hyde, and E. LaDue. 2002. Dairy farm management and long-term farm financial performance. Agric. Resour. Econ. Rev. 31:233-247.

Greene, W. 2011. Fixed effects vector decomposition: a magical solution to the problem of time-invariant variables in fixed effects models. Polit. Anal. 19:135-146.

Hadrich, J. C., C. Wolf, and K. K. Johnson. 2017. Characterizing U.S. dairy farm income and wealth distributions. Agr. Financ. Rev. 77:64-77.

Harrell, F. E. 2001. Regression Modeling Strategies: With Applications to Linear Models, Logistic Regression, and Survival Analysis. Springer, New York, NY

Hausman, J. A., and W. E. Taylor. 1981. Panel data and unobservable individual effects. Econometrica 49:1377-1398.

Hirschman, A. O. 1964. The paternity of an index. Am. Econ. Rev. 54:761-770.

Hoop, D., A. Zorn, M. Lips, and C. Gazzarin. 2015. Determinants of full costs of dairy production in Switzerland - a comparison of two disproportionate joint costs allocations. Selected paper, 20th International Farm Management Congress. July 12-17, 2015. Québec City, Canada. Manitoba Forage and Grassland Association (MFGA), Quebec, Canada.

Kato, K., A. F. Galvao, and G. Montes-Rojas. 2012. Asymptotics for panel quantile regression models with individual effects. J. Econom. 170:76-91.
Kauffman, J. B., and L. W. Tauer. 1986. Successful dairy farm management strategies identified by stochastic dominance analysis on farm records. Northeast. J. Agric. Resour. Econ. 15:168-177.

Khanal, A., and A. K. Mishra. 2016. Are all farms better-off growing organic? An unconditional quantile regression approach. Selected paper, Annual Meeting Agricultural and Applied Economics Association. July 31-August 2, 2016. Boston, MA. Agricultural and Applied Economics Association. Boston, MA.

Kim, M.-O., and Y. Yang. 2011. Semiparametric approach to a random effects quantile regression model. J. Am. Stat. Assoc. 106:1405-1417.

Koenker, R. 2004. Quantile regression for longitudinal data. J. Multivariate Anal. 91:74-89.

Koenker, R., and G. Bassett. 1978. Regression quantiles. Econometrica 46:33-50.

Koenker, R., and G. Bassett. 1982. Robust tests for heteroscedasticity based on regression quantiles. Econometrica 50:43-61.

Lamarche, C. 2010. Robust penalized quantile regression estimation for panel data. J. Econom. 157:396-408

Lips, M., and C. Gazzarin. 2016. Die finanziellen Auswirkungen von Investitionen im Vorfeld abschätzen. Agrarforsch. Schweiz 7:150155. (Ex-ante evaluation of the financial effects of investments.).

Macdonald, K. A., D. Beca, J. W. Penno, J. A. S. Lancaster, and J. R. Roche. 2011. Short communication: Effect of stocking rate on the economics of pasture-based dairy farms. J. Dairy Sci. 94:25812586 .

Mishra, A. K., and M. J. Morehart. 2001. Factors affecting returns to labor and management on U.S. dairy farms. Agr. Financ. Rev. 61:123-140.

Mundlak, Y. 1978. On the pooling of time series and cross-section data. Econometrica 46:69-85.

Nix, J. 2015. Farm Management Pocketbook. 46th ed. Agro Business Consultants Ltd., Melton Mowbray, UK.

RKGK. 2017. Die Gebirgskantone. [The mountain cantons.] Accessed Jul. 19, 2017. http://www.rkgk.ch/.

Roesch, A. 2015. Impact of the SO threshold on the statistics of economic variables for the Swiss agricultural sector. Ger. J. Agric. Econ. 64:33-41.

Schweizer Milchproduzenten. 2014. Schweizer Milchstatistik 2014. [Swiss dairy statistics 2014.] Accessed Jun. 19, 2017. https:// www.swissmilk.ch/de/produzenten/milchmarkt/zahlen-fakten/ statistiken/-dl-/fileadmin/filemount/uploads/content/publikation -milchstatistik-der-schweiz-2014-de.pdf.

Swiss Confederation. 1991. Gewässerschutzgesetz. [Water Protection Act.] Accessed Feb. 22, 2018. https://www.admin.ch/opc/en/ classified-compilation/19910022/index.html.

Tauer, L. W. 2016. Chapter 4: Production response in the interior of the production set. Pages 71-82 in Productivity and Efficiency Analysis. W.H. Greene, L. Khalaf, and R. C. Sickles, eds. Springer, Basel, CH.

Vandehaar, M. J. 1998. Efficiency of nutrient use and relationship to profitability on dairy farms. J. Dairy Sci. 81:272-282.

Wagner, H. M. 1959. Linear programming techniques for regression analysis. J. Am. Stat. Assoc. 54:206-212.

Wang, H. J., and M. Fygenson. 2009. Inference for censored quantile regression models in longitudinal studies. Ann. Stat. 37:756-781.

Winsten, J. R., R. L. Parsons, and G. D. Hanson. 2000. A profitability analysis of dairy feeding system in the Northeast. Agric. Resour. Econ. Rev. 29:220-228. 
APPENDIX

\section{Construction of the Inverse Hirschman- Herfindahl Index}

The original Hirschman-Herfindahl index $\left(\mathbf{H H I} ; H_{0}\right.$; Hirschman, 1964) is given by

$$
H_{0}=\sum_{i=1}^{N}\left(\frac{s_{i}}{s}\right)^{2} \in\left[\frac{1}{N} ; 1\right],
$$

with

$$
s=\sum_{i=1}^{N} s_{i}
$$

The quantities $s_{i}$ are generic variables whose concentration should be assessed. In our case, they are taken as revenues generated by a diverse set of farming operations; for example, crop production, animal production except dairying, or activities related to agriculture. As HHI measures concentration and we are interested in diversification, we invert the HHI to obtain an inverted HHI as

$$
H_{i}=1 / H_{0}, \text { with } 1 \leq H_{i} \leq N .
$$

Subsequently, normalization is carried out to yield

$$
H_{i}^{n}=\left(H_{i}-N\right) /(1-N),
$$

with

$$
0 \leq H_{i}^{n} \leq 1
$$

\section{Overview of Certain Statistical Properties of the Set of Explanatory Variables}

Tables A1 and A2 show the variance, mean values, and mean decile values of explanatory and explained variables.

\section{Correlations of Explanatory Variables and the Error Term of the Random Effects Model}

Table A3 shows correlations and their significance between the error terms of the random effects model computed in different manners, namely direct computation or assessment of coefficients of a pooled ordinary least squares regression or a new random effects model between the error terms and each of the explanatory variables. Results show that endogeneity is not an issue except potentially for natural grassland, where it is ruled out by the Mundlak and Hausman-Taylor model. 
Table A1. Variance and breakdown into cross-sectional and temporal components of explanatory and explained variables

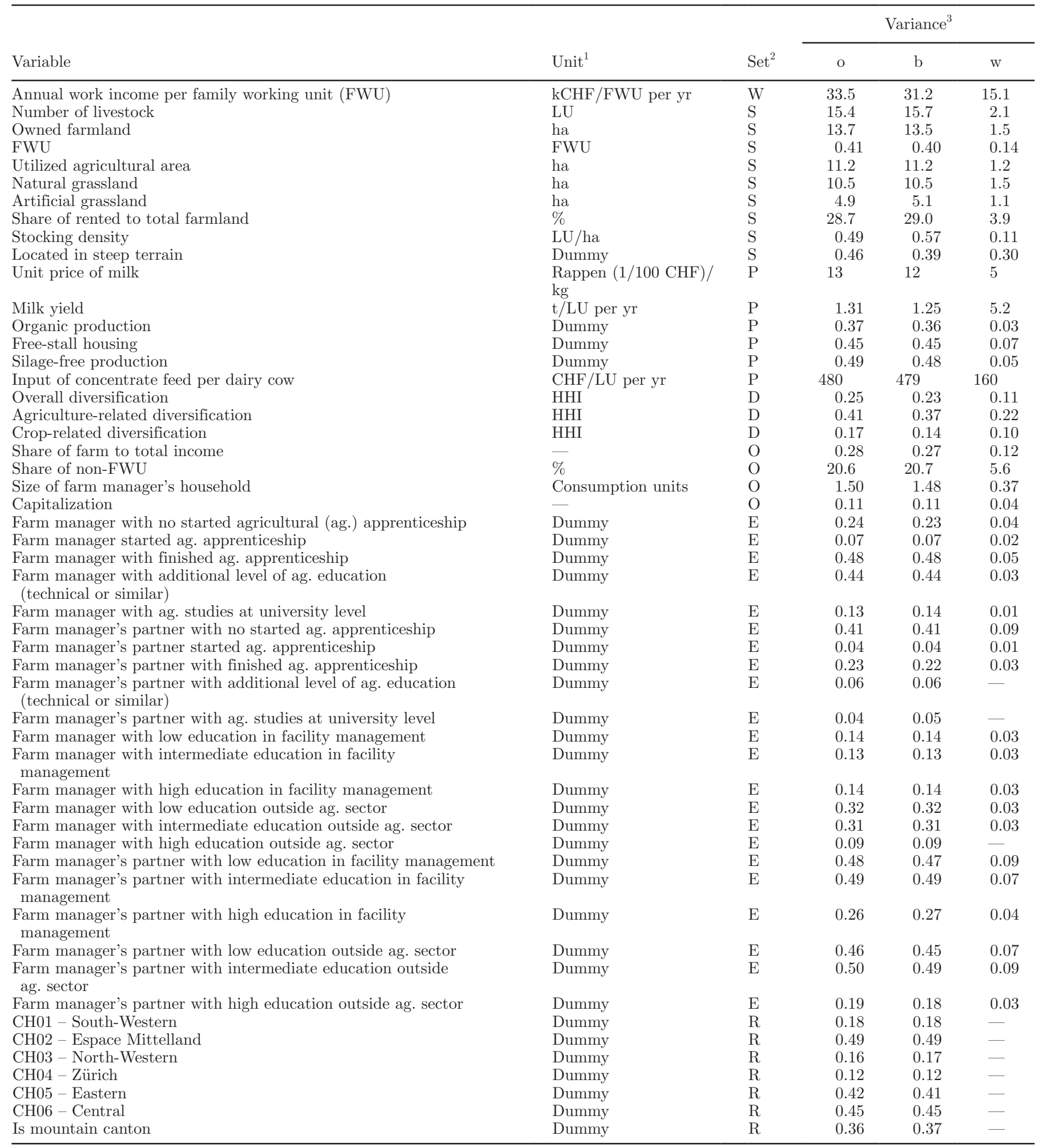

${ }^{1} \mathrm{LU}=$ livestock units; HHI = Hirschman-Herfindahl index.

${ }^{2} \mathrm{~W}=$ work unit income per FWU; $\mathrm{S}=$ structural situation; $\mathrm{P}=$ production techniques; $\mathrm{D}=$ diversification; $\mathrm{O}=$ organizational and financial factors associated with running a farm business; $\mathrm{E}=$ education level of the farm operator and his or her partner; $\mathrm{R}=$ regional dummies.

${ }^{3} \mathrm{O}=$ overall variance; $\mathrm{b}=$ between (cross-sectional) variance; $\mathrm{w}=$ within (temporal) variance. 


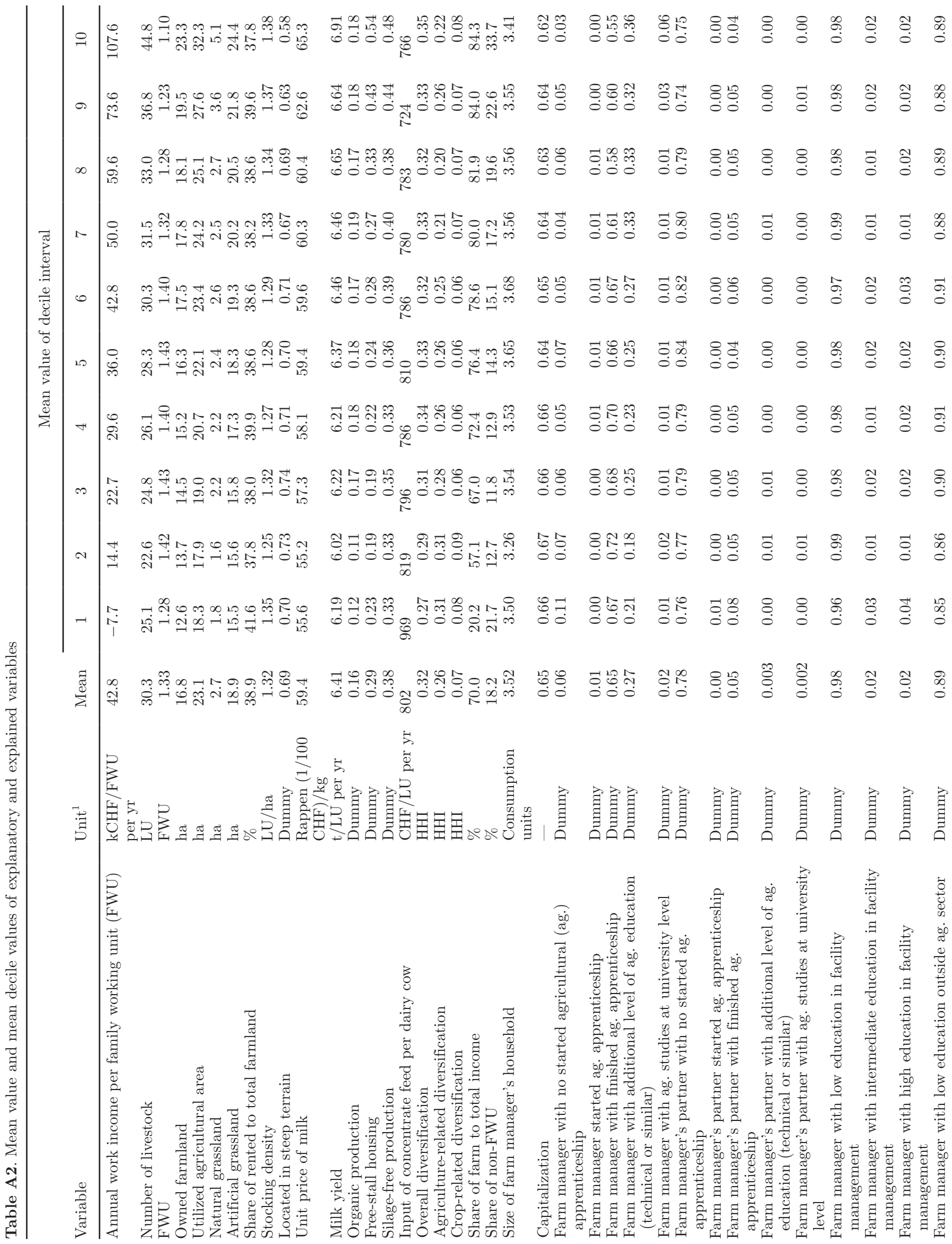




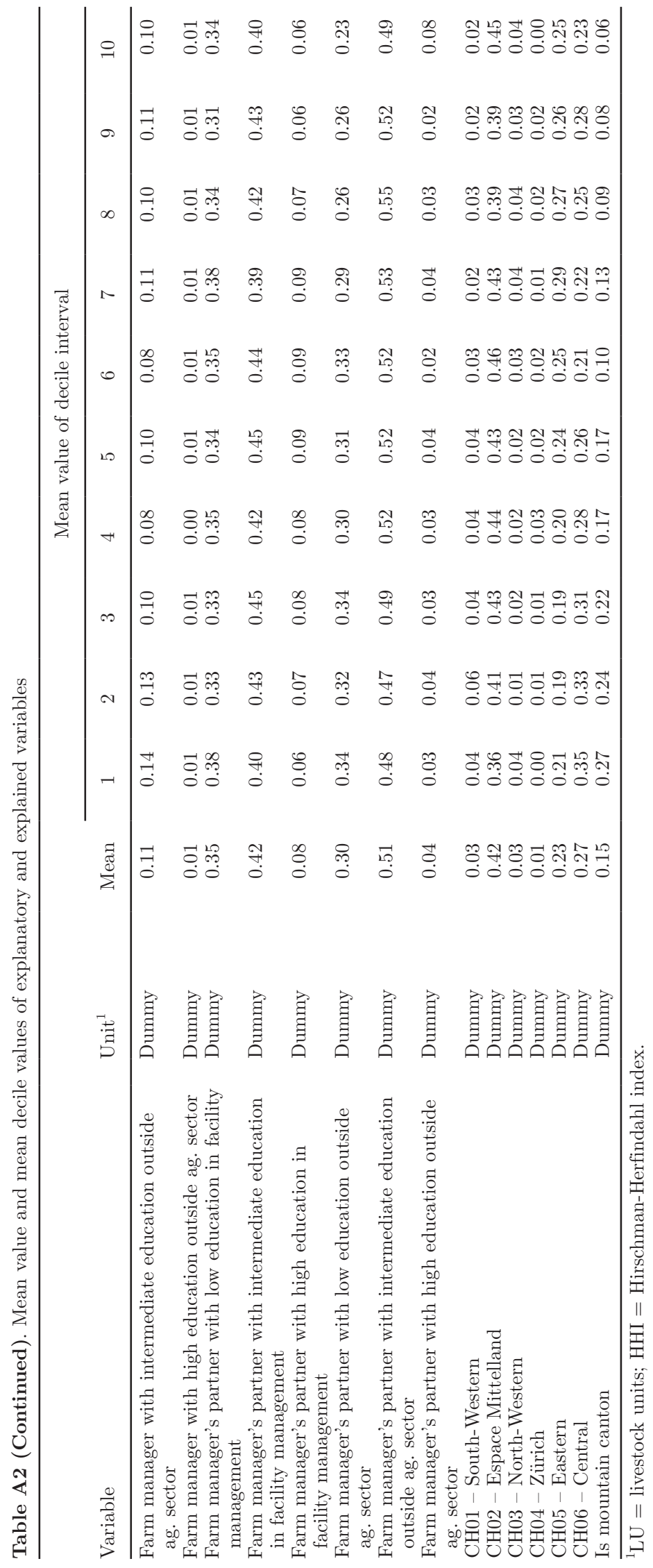



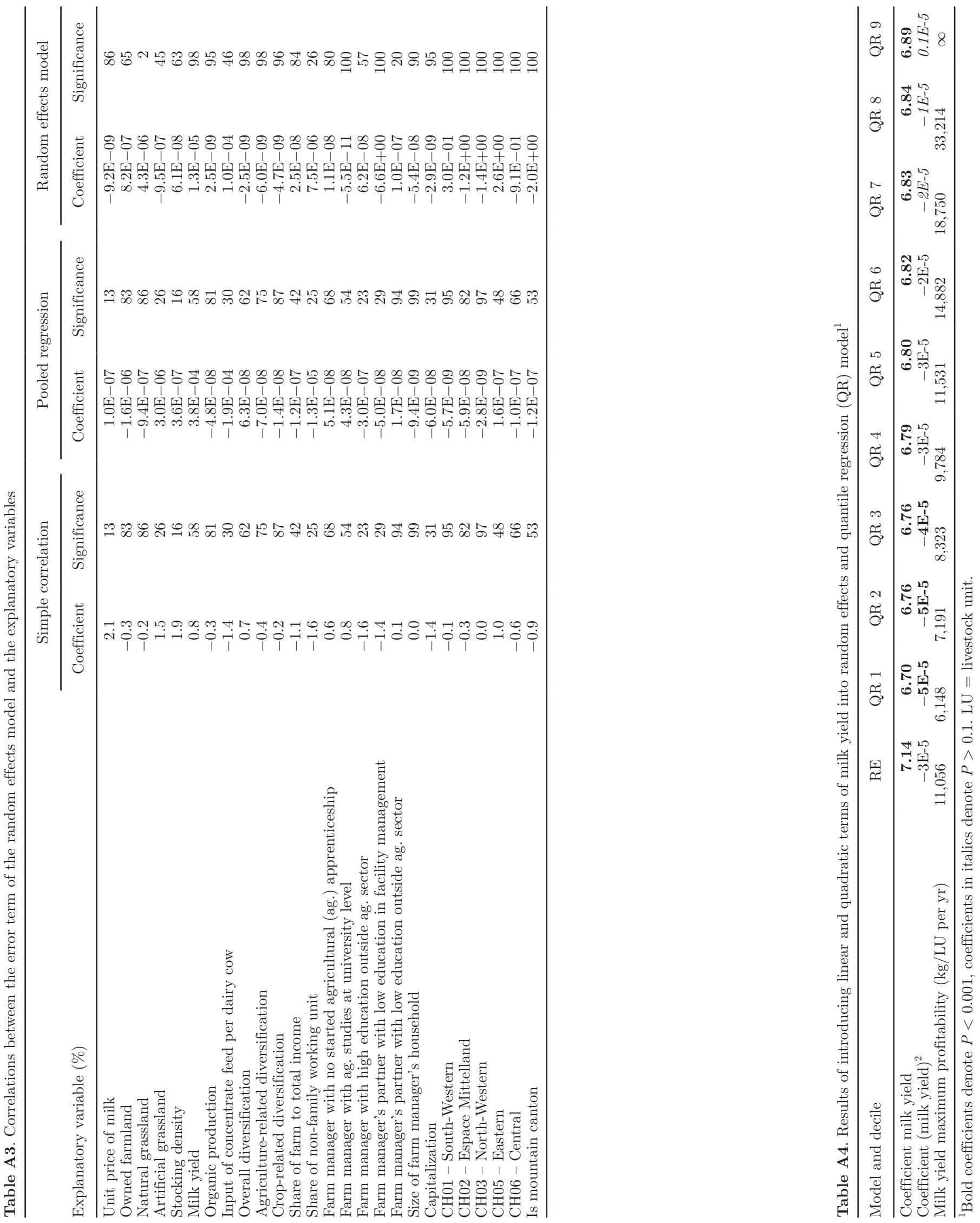